\title{
É POSSÍVEL PRODUZIR UM COMUM NO DISSENSO? AS “TRETAS VIRTUAIS" COMO CAMINHOS PARA PENSAR A POLÍTICA HOJE - O CASO CASA NUVEM-CASA NEM
}

\section{IS IT POSSIBLE TO PRODUCE THE COMMONS THROUGH DISSENT? ONLINE CONFLICTS AS ROUTES TO THE UNDERSTANDING OF CONTEMPORARY POLITICS - THE CASA NUVEM-CASA NEM CASE}

\author{
Fernando do Nascimento GONÇALVES ${ }^{1}$; Paula Gorini OLIVEIRA ${ }^{2}$
}

Resumo: Este trabalho tem por objetivo discutir a disputas de narrativa online, como característica de disputas mais amplas e multisituadas que se dão em rede, a partir de um caso: a passagem não-consensual Casa Nuvem - Casa Nem. O enfoque teórico se desenvolve a partir das ideias de "dissenso" e de "comum", que neste trabalho se apresentam como potentes meios de conectar a observação do caso analisado com as produções atuais da política, especialmente no que diz respeito aos movimentos sociais e lutas políticas. A análise também é observada pelo seu aspecto sociotécnico, que implica pensar a relação e interação entre redes digitais e presenciais, construindo uma observação em rede, metodologicamente embasada na Teoria do Ator-Rede, TAR.

Palavras-chave: Dissenso; Comum; Disputas em rede; Política.

Abstract: This paper aims to discuss online narrative disputes, as a characteristic of broader and multi-centered disputes which are networked, from a case study: the nonconsensual transition of Casa Nuvem to Casa Nem. The theoretical approach is developed by the ideas of "dissent" and "common", which in this work are presented as powerful pathways of connecting the analyzed case with the current productions of politics, especially concerning to social movements and political struggles. The analysis is also observed by its sociotechnical aspect, which implies thinking about the relationship and interaction between digital and physical networks, building a network approach, methodologically based on the Actor-Network Theory, ANT.

Keywords: Dissent; Common; Online conflicts; Politics.

\footnotetext{
${ }^{1}$ Doutor em Comunicação e Cultura pela UFRJ com pós-doutorado em Sociologia do Cotidiano pela Universidade Paris V- Sorbonne. Professor associado do PPGCOM-Uerj, coordenador do GT de Estudos de Cinema, Fotografia e Audiovisual da Compós e artista visual. E-mail: goncalvesfernandon@gmail.com.

${ }_{2}$ Doutoranda do Programa de Pós-Graduação em Comunicação da Universidade do Estado do Rio de Janeiro (PPGCOM/ UERJ). E-mail: paulagorini@gmail.com.
} 


\section{Introdução: $O$ Desentendimento e as disputas em rede}

Por desentendimento entenderemos um tipo determinado de situação da palavra: aquela em que dois interlocutores ao mesmo tempo entende e não entende o que diz o outro. O desentendimento não é o conflito entre aquele que diz branco e aquele que diz preto. É o conflito entre aquele que diz branco e aquele que diz branco, mas não entende a mesma coisa, ou não entende de modo nenhum que o outro diz a mesma coisa com o nome de brancura. (RANCIÈRE, 1996, p. 11)

Este texto discute o dissenso como cerne da política e ao mesmo tempo como possibilidade da construção de um "comum" não consensuado no contexto das lutas por direitos sociais e políticos no momento atual. O caso que serve como ancoragem para a discussão é a passagem (não consensual), ocorrida em 2016, da Casa Nuvem - espaço que reunia um grupo de pessoas e projetos que atuavam principalmente no campo da arte, cultura e do ativismo político -, pela ocupação do que atualmente funciona como Casa Nem - espaço de atendimento e acolhimento temporário para pessoas transexuais em risco social e de produção de projetos e eventos com enfoque principalmente em questões LGBTI, ambos sediados num antigo sobrado na Lapa, centro da cidade do Rio de Janeiro.

Partindo da descrição das dinâmicas das disputas de narrativas produzidas e replicadas no Facebook, no contexto da passagem dissensual Casa Nuvem - Casa Nem, consideraremos essas disputas como parte de uma disputa mais ampla e que denominaremos "disputas em rede"2. Tal disputa será considerada aqui como um fenômeno comunicativo contemporâneo relacionado a conflitos sociais e políticos, observados a partir de redes de relações diversas que se manifestam através das redes digitais e presenciais. $\mathrm{O}$ objeto se apresenta como forma de refletir sobre as relações que se constroem na política e que são por ela construídas a partir de conflitos.

Como veremos, a passagem "Casa Nuvem - Casa Nem” tem como característica a produção de narrativas que recorrem a discursos de violência e denúncias de ambos os lados, publicizados principalmente no Facebook. Num primeiro momento, o Facebook funciona como uma espécie de "arena" política, onde os conflitos se tornam evidentes e públicos. Mas, num segundo momento, a plataforma passa também a ser um espaço de regulação das dinâmicas destes conflitos, na reverberação de discursos ali produzidos,

\footnotetext{
2 O tema das "disputas em rede" está sendo trabalhado mais diretamente na investigação de tese da autora Paula Gorini, cujo orientador é o co-autor Fernando Gonçalves.
} 
na produção de narrativas, no compartilhamento e mobilização via hashtags. Os discursos produzidos, replicados e disputados na rede digital se amplificam e se estendem para o espaço fora da rede online, em eventos e debates que parecem dar continuidade aos conflitos iniciados no digital.

O termo desentendimento, contido na citação do filósofo Jacques Rancière, que abre o artigo, está sendo tratado como inspiração para pensar situações de conflito que tangem o caso Casa Nuvem - Casa Nem, em particular, mas também as construções das experiências da política hoje. Essa noção de desentendimento em Rancière vai interessar sobretudo por nos ajudar a refletir sobre os impasses e as possibilidades da produção de um "comum" nesses contextos de lutas políticas na atualidade. E, de partida, desejamos dizer que por "comum" não estamos entendendo algo que é partilhado consensualmente e que atribui à experiência de pessoas e grupos um sentido de unidade, mas um tipo de laço que dá coesão e mantém as coisas unidas pela tensão das diferenças e que se constrói nos processos de vinculação social e que não pré-existe a eles, como propõe Sodré (2014, p. 207).

Em "O Desentendimento" (1996), Rancière faz uma discussão sobre o pensamento filosófico da política, cujo enfoque não é o de analisar conflitos, mas partir de questões pertinentes ao debate filosófico como meios de acessar o dizer e o fazer da política. Ele explica:

\begin{abstract}
A filosofia torna-se "política" quando acolhe a aporia ou o embaraço próprio da política. A política [...] é a atividade que tem por princípio a igualdade, e o princípio da igualdade transforma-se em repartição de parcelas de comunidade ao modo do embaraço: de quais coisas há e não há igualdade entre quais e quais? O que são essas "quais", quem são esses "quais"? De que modo a igualdade consiste em igualdade $e$ desigualdade? Tal é o embaraço próprio da política, pelo qual a política se torna um embaraço para a filosofia, um objeto da filosofia. (RANCIĖRE, 1996, p. 11, grifo do autor)
\end{abstract}

Nesta obra, especificamente, o autor aborda as discussões acerca da palavra, da argumentação, e diferencia desentendimento de "mal-entendido", ou de "desconhecimento", ou, como explica, "os casos de desentendimento são aqueles em que a disputa sobre o que quer dizer falar constitui a própria racionalidade da situação da palavra”. (RANCIÈRE, 1996, p. 12). Ainda que não seja nosso enfoque fazer uma discussão aprofundada do conceito, este nos ajuda a pensar as dinâmicas das disputas de narrativas, produzidas e replicadas nos sites de redes sociais no contexto da passagem Casa Nuvem - Casa Nem como ponte e base para reflexões acerca da experiência da política hoje. 
Partimos das premissas de que o caso em análise se expressa principalmente por sua característica complexa e multisituada e de que, ao se inscrever na lógica de publicação do Facebook, acaba por se dividir em polaridades, como lados "contra" ou "a favor" (Casa Nuvem x Casa Nem). Buscaremos discutir aqui, ainda que brevemente, como se dão tais disputas, e como se formulam as lógicas de produção e divulgação de narrativas apresentadas por esses dois "lados". E o que (ou se) essas lógicas de comunicação mediadas por tecnologias digitais revelam sobre o fazer e o dizer da política hoje.

Nossa aposta é de que há de fato uma transformação em jogo no cenário dos chamados novos movimentos sociais e políticos (MELUCCI, 1999; GOHN, 2003), nas lutas políticas que se dão nas ruas, em que emerge um novo sujeito político, fragmentado e descentralizado. Juntamente com os movimentos de rua descentralizados emergem novas formas de se fazerem ecoar vozes sociais que foram historicamente e socialmente constituídas como minorias. Estas vozes encontram cada vez mais em espaços como o Facebook terreno fértil para serem potencializadas, ao mesmo tempo em que nele são redimensionadas como discursos políticos que atuam por ações de comunicação e de mobilização, como campanhas de hashtags, memes e virais.

É partir das tensões que surgem entre potencializações e redimensionamentos que tais vozes são também são transformadas e recompostas em narrativas polarizadas ou lados (frequentemente opostos), que geram intermináveis disputas online, as assim chamadas "tretas virtuais", com as quais acaba-se por perder de vista diversas nuances e camadas que se escondem por traz da linearidade da expressão bipartida e polarizada desses conflitos. O que o artigo pretende é justamente discutir o caso "Casa Nuvem Casa Nem" como forma de verificar algumas dessas premissas, cruzar ideias e teorias, e apresentar contornos iniciais ao debate da produção política hoje, no tensionamento entre as figuras do "dissenso" e do "comum".

Neste aspecto, parece coerente pensar o desentendimento não como duas ideias diferentes em choque, mas como duas ideias iguais que não conseguem se comunicar, nem falar nem escutar. É sobre essa perspectiva, inspirada pela ideia de "conflito entre aquele que diz branco e aquele que diz branco, mas não entende a mesma coisa, ou não entende de modo nenhum que o outro diz a mesma coisa com o nome de brancura" (RANCIERE, 1996, p.11), que o artigo será desenvolvido. 


\section{O caso Casa Nuvem - Casa Nem}

A controvérsia que inaugura as disputas de que estamos tratando aqui é a interrupção do espaço Casa Nuvem por um acontecimennto/acidente que culminou com a ocupação do que atualmente funciona como Casa Nem. Tomamos emprestado o conceito de "acidente" da antropóloga Fernanda Eugênio (2014), em que acidente é começar pelo meio, "começar pelo imprevisível, ou melhor: começar justo aí, no imprevisível, nesse lugar-situação envolvente em que acidente e acidentado irrompem e se interrompem mutuamente..." (PASSOS et al, 2014: 289). O acidente que dá início à investigação é tomado também como um acontecimento, que já desde o início força uma paragem e ao mesmo tempo produz relações.

Em fevereiro de 2016, durante a festa de carnaval da Casa Nuvem (2016), há uma denúncia de transfobia sofrida por uma das transexuais que frequentava a casa, aluna do projeto PreparaNem ${ }^{3}$. Durante a festa, a mulher trans que sofreu a opressão tem a mão gravemente cortada. Os participantes do coletivo da Casa Nuvem que estavam presentes durante o acidente/acontecimento do carnaval, segundo relatos, socorreram a vítima, que foi conduzida para o segundo andar da casa, onde foram prestados os primeiros socorros, e depois conduzida à emergência hospitalar. A associada responsável pelo PreparaNem, Indianara Siqueira, foi acionada por telefone e se dirigiu também à Casa Nuvem. Ao chegar, pediu ao DJ que parasse a música para que fizesse um pronunciamento geral. O DJ respondeu que a festa estava acabando e não parou a música. A energia da casa foi desligada e o pronunciamento foi feito por Indianara.

A festa de carnaval havia sido inicialmente programada para levantar recursos financeiros para sustentabilidade da casa, era aberta ao público geral, e tinha no bar sua principal fonte de retorno financeiro. Este evento marca a cisão entre o grupo que participava da Casa Nuvem, que passa a ser acusado de transfobia e a ocupação que toma forma alguns dias depois, liderada pela ex-associada Indianara Siqueira, acompanhada de outras participantes do projeto PreparaNem. Na manhã de sábado do dia seguinte da festa, começam a se espalhar pelo Facebook publicações de denúncia

\footnotetext{
3 Descrição no "sobre" da página do Facebook: "Eventos e preparatório pro Enem para pessoas trans, travestis e/ ou em situação de vulnerabilidade social e preconceito de gênero." Disponível em: https://www.facebook.com/pg/PreparaNem/about/?ref=page internal, acesso em: 25/04/2018.
} 


\section{míDiA \\ eCOti \\ DiAno}

contra a Casa Nuvem: "Purpurina vira sangue na Casa Nuvem" (Fig.1), e depois, "Casa Nuvem Transfóbica"; "Boicote ao bar da Casa Nuvem".

Figura 1 - Purpurina e sangue na Casa Nuvem

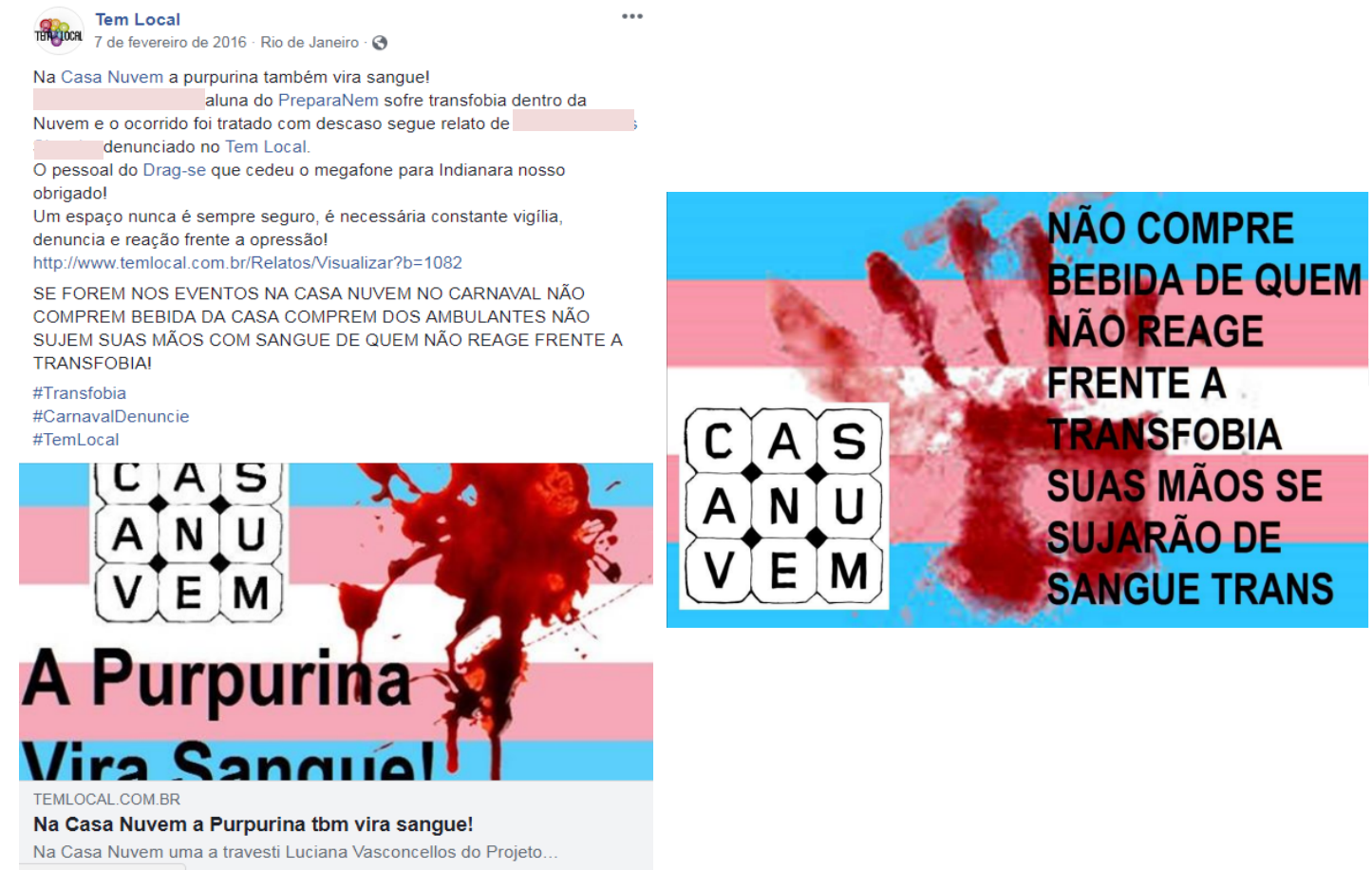

Fonte: printscreen de publicações do Facebook, 07/02/2016.

As figuras acima representadas chamam a atenção principalmente por seu apelo imagético. Podemos ver a bandeira do movimento trans como pano de fundo, uma marca de mão de sangue e a logo da Casa Nuvem. As palavras "purpurina" e "sangue", na primeira imagem, também possuem uma força imagética, já que remetem a ideias bem reconhecidas, o sangue do corpo e a purpurina do carnaval. A segunda imagem é um protesto: "Não compre bebida de quem não reage frente a transfobia..." [sic]. Mas há no texto que acompanha a publicação, na primeira imagem, uma frase que chamou nossa atenção: "Um espaço nunca é sempre seguro, é necessário constante vigília, denúncia e reação contra a opressão!”. Esta frase parece dar uma pista sobre uma "partilha" que está em jogo: uma fala exclusiva em relação à Casa Nuvem, "um espaço nunca é sempre seguro", que reflete a produção de um outro "comum" da Casa Nem "transfobia mata". 
Para Rancière, em seu debate sobre as relações entre estética e política, em "A Partilha do Sensível" (2005), o sensível é tudo aquilo que percebemos, sentimos e experienciamos não como algo dado, mas como algo que é objeto de uma disputa, de uma divisão e também de uma construção em comum. Para o autor, a partilha do sensível é um "sistema de evidências sensíveis que revela, ao mesmo tempo, a existência de um comum e dos recortes que nele definem lugares e partes respectivas. Uma partilha fixa, portanto, ao mesmo tempo, um comum partilhado e partes exclusivas" (RANCIÈRE, 2005, p.15, grifo nosso).

Diante da denúncia de transfobia, os participantes da Casa Nuvem respondem inicialmente de forma pouco articulada, com respostas em comentários de forma individualizada. E, após reunião realizada em caráter emergencial, decide-se fechar as portas da Casa no domingo de carnaval (a festa tinha programação prevista para durar até a quarta-feira de cinzas). Neste ponto, há a produção de um texto coletivo e explicativo sobre o fechamento, com uma "nota de esclarecimento", onde o grupo então responsável pelo espaço apresenta sua perspectiva sobre o ocorrido. Abaixo a reprodução de parte do texto, que também serve como uma evidência da narrativa que a Casa Nuvem produz sobre si:

\begin{abstract}
Consideramos importante reiterar publicamente a nossa postura e a forma de estar na cidade. Enquanto coletivo, que atua de forma experimental com o espaço da casa e da cidade, acreditamos ser importante deixar claro que nenhum ato de transfobia é ou será aceito, assim como nenhum outro tipo de opressão e violência, física ou psicológica. Acreditamos que a Casa Nuvem é formada por todxs que a frequentam, participam de projetos e causas, bem como pelos associados que trabalham continuamente para a sustentabilidade e manutenção das ações da Casa. (Casa Nuvem/ Facebook, 08/02/2016) ${ }^{4}$
\end{abstract}

A nota de esclarecimento também fornece pistas sobre a mesma partilha de que antes falávamos, ou seja, sobre a produção de partes exclusivas e de partes comuns. No que tange ao discurso político da causa LGBTI, na produção de um "comum", a nota declara: "nenhum ato de transfobia é ou será aceito...". Esta declaração posiciona a Casa Nuvem na relação que a mesma estabelece com o movimento trans. Mais abaixo, no texto da nota, há um trecho que indica sua partilha exclusiva: “... a Casa Nuvem é formada por todxs que a frequentam..." [sic]. A ideia de "todos" parece chamar à responsabilidade não apenas os associados, mas também o público, participantes e frequentadores, e é reforçada pela grafia do "x", “todxs". Esta declaração posiciona a

\footnotetext{
${ }^{4}$ Disponível em: https://www.facebook.com/casanuvem/posts/1096115697098775
} 
Casa Nuvem como parte exclusiva, não é qualquer casa, ou qualquer espaço, é um espaço que produz um "comum", junto com o movimento trans. E inclui os responsáveis pela festa de carnaval, o dj que não parou a música, as pessoas que prestaram socorro, as pessoas que fazem a denúncia online por transfobia, e até mesmo a adoção da grafia inclusiva, que troca a letra "o" por " $x$ ". 5

A parte exclusiva diz respeito à narrativa que a Casa Nuvem produzia sobre si, um espaço seguro para diversidade sexual e de gênero, um espaço onde não se aceita transfobia. Mas, ao confrontar com o texto da primeira imagem, (Fig. 1), percebemos que também a Casa Nem produz sua partilha: a afirmação de que um "espaço nunca é sempre seguro" coloca o "comum" da Casa Nuvem em perspectiva: primeiramente, é seguro para quem? E se é seguro, o é até certo ponto, não é seguro depois de certo limite. O limite, no caso, é reivindicado pelas próprias pessoas que sofrem a opressão, no caso, a população transexual e travesti que frequentava o projeto PreparaNem e que faz a denúncia no Facebook. Com isso, a Casa Nem constrói também partes comuns ("transfobia mata") e exclusivas ("Não comprem bebida de quem não reage à transfobia (...)"). A Casa Nuvem responde, em sua parte exclusiva, que é formada por "todxs que a frequentam".

Observamos assim que ambas parecem desejar produzir um "comum" idealizado e centrado, na verdade, em pontos de vista exclusivos, que coloca visões e desejos diferentes como se fossem únicos e consensuados. No caso, tudo aquilo que diz respeito à luta contra a opressão e contra a transfobia, porque esta "mata", porque "suas mãos se sujarão de sangue trans", e ao mesmo tempo porque "nenhum ato de transfobia é ou será aceito", "A Casa Nuvem é formada por todos que a frequentam".

Observamos nessas disputas de narrativa exatamente o que Rancière chamou de dissenso. O "comum" nessa disputa parece refletir um "falar por" que supostamente coloca o outra numa posição de concordância, quando na verdade é o contrário. E isso acontece dos dois lados. Trata-se de um aparente paradoxo: ambos os lados estão falando a "verdade" e dizendo que a sua verdade é "comum" a todos. Expressão clara de um dissenso, o que a disputa em análise talvez esteja demonstrando é que o "comum"

\footnotetext{
${ }^{5} \mathrm{Na}$ língua portuguesa indica-se concordância de gênero, no masculino, sempre quando há pessoas dos gêneros masculino e feminino implicadas na frase. O uso da grafia " $x$ ", ou às vezes "e", indica não apenas a inclusão de um terceiro gênero, o não binário, mas principalmente um posicionamento político em relação a hierarquia historicamente constituída para o gênero masculino.
} 
nesse caso é a própria disputa, mas que, ainda assim, no meio dessa disputa, talvez seja possível construir, ainda que temporariamente, espaços de fala e práticas não consensuais mas de vizinhança, de coesão de diferenças.

O que podemos ver com estes recortes sobre o material que é compartilhado via Facebook é que as partilhas entre aquilo que é exclusivo de um ou outro ator, Casa Nuvem/ Casa Nem, e a produção de um comum compartilhado entre estas duas casas, duas iniciativas, não estão dadas de antemão. As partilhas em partes exclusivas e comuns são disputadas na manifestação de vozes, na articulação de discursos, na publicização de ideias e imagens. O comum partilhado é disputado e produzido no dissenso.

\section{Procedimentos metodológicos, ou como criar uma ordem para manter as controvérsias?}

No objeto aqui investigado há uma gama de controvérsias que se conectam a partir de um acontecimento, se apresentam por disputas de narrativas, em atos, imagens, lugares e falas, e apontam para um momento atual da experiência política em nossa sociedade. Partindo das ditas "tretas virtuais" no Facebook como material de análise, busca-se investigar como se dão as dinâmicas das disputas de narrativas em redes on e offline, de onde surgem, como se organizam e como se propagam tanto pelo Facebook quanto por encontros e situações presenciais.

Mas a noção de rede empregada aqui não se confunde com a de rede da internet ou das redes sociais, mesmo se é a partir delas que as relações e produções de vínculos sociais e políticos que nos interessam se manifestam. A noção de rede que empregamos aqui vem da abordagem da Teoria do Ator-Rede, (TAR), desenvolvida por vários autores, e sistematizada por Bruno Latour. Para estes autores, rede não se resume apenas à estrutura, ou sistema, mas a uma rede de relações em que os fenômenos sociais se apresentam. Pela perspectiva da TAR, o meio de acessar as várias camadas que mobilizam o social e se apresentam como uma rede de relações é através do acompanhamento do objeto e da descrição dos atores implicados, que se apresentam normalmente por controvérsias, no caso, as tretas virtuais a partir da treta presencial Casa Nuvem-Casa Nem.

Segundo Latour (2008), as controvérsias são parte constantes das agregações sociais, que muitas vezes não são levadas em conta por uma tradição científica que 
delimita os fenômenos sociais de antemão em categorias rígidas e fechadas. Rastrear as controvérsias é algo que pode nos falar mais sobre o social do que tentar explicar os fenômenos em estudo e encaixá-los em categorias teóricas e analíticas préestabelecidas. Essa é forma de abordagem da TAR, ou como explica Latour:

[...] em vez de adotar uma posição razoável e impor uma ordem por antecipação, a TAR sustenta que está em melhores condições de encontrar ordem depois de deixar que os atores se desdobrem de toda gama de controvérsias nas quais estão imersos. [...] A tarefa de definir e ordenar o social deve ser deixada aos próprios atores, e não ao analista. É por isso que, para recuperar algum sentido de ordem, a melhor solução é rastrear as relações entre as próprias controvérsias em vez de tentar dizer como resolver qualquer controvérsia dada. (LATOUR, 2008, p. 42-43, grifo do autor, em tradução livre $)^{6}$

Neste trabalho, o site de rede social Facebook é tomado como a parte mais visível de outras disputas igualmente complexas, não só de narrativas ou entre pessoas, grupos e identidades, mas também entre agendas políticas e lugares de fala. O que a observação "de rede" da TAR nos permite observar a partir do Facebook, portanto, é uma disputa não apenas de narrativas, mas exatamente uma disputa mais ampla, que se dá "em rede", no sentido de uma rede de relações que são multisituadas e de diferentes naturezas. Assim, o conceito de rede empregado aqui abrange conjuntamente o ambiente online e offline, se distribui e se organiza a partir do Facebook, mas também de espaços, encontros, atos e eventos presenciais. E, uma vez conectados, se redistribuem de volta aos ambientes online, num caminho de ida e volta contínuo, formando uma complexa rede de relações (políticas, históricas, de gênero, econômicas, subjetivas, territoriais, simbólicas, etc).

Pela abordagem da TAR, o desafio é o de descrever as controvérsias que envolvem os fatos analisados e as redes de relações que os constroem e que eles constroem. Tal descrição (de agenciamentos e controvérsias) implicaria, assim, o esforço de registrar e analisar os pontos de conexão e de afetação entre atores humanos e não-humanos, os vínculos que se estabelecem entre eles e que resultam nos fatos observáveis, mesmo que estes vínculos e esses fatos sejam instáveis. Seria o que Latour

\footnotetext{
${ }^{6}$ No original: "[...] en vez de adoptar una posición razonable e imponer un orden por anticipado, la TAR sostiene que está en mejores condiciones de encontrar orden después de de haber dejado que los actores desplieguen toda la gama de controversias en las que están inmersos. [...] La tarea de definir y ordenar lo social debe dejarse a los actores mismos, y no al analista. Es por esto que, para recuperar algún sentido de orden, la mejor solución es rastrear relaciones entre las controversias mismas en vez de tratar de decir cómo resolver cualquier controversia dada. De ningún modo se abandona la búsqueda de orden, de rigor e de patrones. Simplemente se resitúan esas búsquedas en un nivel más alto de abstracción, de modo de permitir a los actores desplegar sus propios y diversos cosmos, por más contraintuitivos que parezcan."
} 
chama de "deixar o objeto falar", uma vez que, para a TAR, os atores são performativos, se apresentam em processo e desenham uma rede de relações que está em constante movimento.

Na perspectiva das lutas políticas contemporâneas, como as que se desenvolvem na Casa Nuvem/Casa Nem, é possível observar movimentos sociais que se organizam de forma emergente, ou bottom up, em que o desenvolvimento das tecnologias digitais passa também a mediar relações humanas. Os movimentos que se organizam muitas vezes pela facilidade que as tecnologias digitais propiciam, produzem uma rede de afetos políticos, que se manifestam no encontro presencial e na convivência, no pensamento e ações produzidas a partir desses encontros em atos e manifestações.

Antonio Negri e Michael Hardt, no livro "Isso não é um manifesto" (2016), no capítulo que dedicam às figuras subjetivas da crise, sendo uma delas o "mediatizado", fazem uma reflexão sobre a mediação das tecnologias de comunicação em nosso cotidiano. Para estes autores, as tecnologias são conjuntamente agregadoras e dispersantes. Por um lado, permitem autonomia política e econômica, ou mesmo que grupos, coletivos e indivíduos se organizem a partir da interação online via sites de redes sociais. No entanto, também são responsáveis pela produção de subjetividades fragmentadas e dispersas. Com base nos movimentos de Occupy ao redor do mundo, os autores evocam a presença corporal, a convivência, a troca, a conversa, como fator de agenciamento na construção de laços, os afetos políticos:

\begin{abstract}
O Fecebook, o Twitter, a internet e outros tipos de mecanismos de comunicação são úteis, mas nada consegue substituir o estar junto de corpos e a comunicação corpórea, que é a base da inteligência e da ação política coletiva. Em todas as ocupaç̃es nos Estados Unidos e ao redor do mundo, do Rio de Janeiro a Liubliana, de Oakland a Amsterdã, mesmo nos casos em que elas duraram pouco tempo, os participantes vivenciaram o poder de criar novos afetos políticos por meio do ato de estar juntos. (NEGRI; HARDT, 2016, p. 32, grifo meu)
\end{abstract}

Como vimos, o que caracteriza os afetos políticos não é o consenso. Nesse sentido, apostamos que uma análise de "rede" a partir da TAR para tratar de fenômenos dissensuais no contexto das lutas políticas por direitos hoje não deve buscar simplesmente "ordenar" as controvérsias na forma de explicações normativas ou totalizantes, mas deixar que estas conduzam nossas observações e análises.

\title{
Os lugares de fala e a construção do comum para minorias socialmente constituídas
}




\section{eCOti DiAno}

Observe na figura abaixo (FIG.2) a publicação que dá início à ocupação da Casa Nuvem pela Casa Nem:

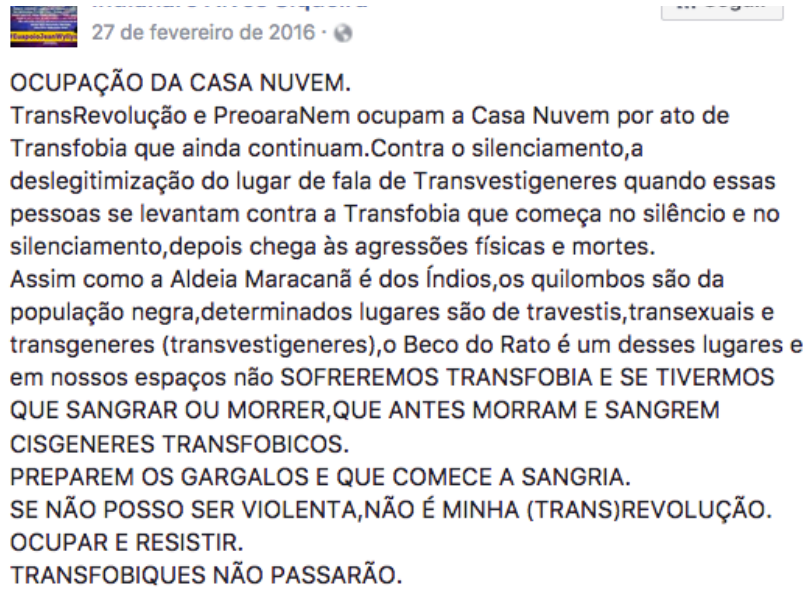

Figura 2: Ocupação da Casa Nuvem

Fonte: Printscreen de publicação no Facebook, 26/02/ 2016.

$\mathrm{Na}$ figura apresentada acima, a reivindicação de lugares de fala pode ser sublinhada pela frase: “Assim como a Aldeia Maracanã é dos índios, os quilombos são da população negra, determinados lugares são das travestis, transexuais e transgeneres (transvestigeneres), o Beco do Rato é um desses lugares..." [sic]. Vale observar que a figura reproduzida apresenta os termos políticos estratégicos do movimento trans, "transexuais" e "transgêneres", e uma variação deste último, "transvestigênere". A estratégia é enfatizada pela grafia do "e" no lugar de "o", tanto para o termo "transgênerō", quanto para sua variação "transvestigênerọ".

No caso da imagem apresentada, os termos estratégicos do movimento LGBTI reivindicam o território simbólico, discursividades produzidas e/ou propagadas em ambientes virtuais e presenciais, que reforçam processos de identificação a partir de termos usados na luta política. São eles mesmos, os termos e as palavras, agenciamentos que conectam posicionamento político com estratégias de lutas. Da mesma forma, o texto reivindica para si (para as transexuais e travestis) o Beco do Rato, por seu contexto histórico e social, como território físico.

As opressões sociais podem ser observadas a partir de relações de poder que se estabelecem entre grupos sociais e são debatidas principalmente por sua constituição não apenas individual, mas estrutural. Ou seja, pela perspectiva da transfobia, a 
opressão contra transexuais, e população LGBTI como um todo, se torna evidente não apenas por atos isolados de indivíduos, mas pela forma mesmo como a sociedade está organizada, que permite, ou não, que estes grupos acessem cidadania. Discussão que também está presente no debate sobre "lugar de fala", embasado teoricamente no trabalho de Djamila Ribeiro (2017). A filósofa e ativista do feminismo negro explica a questão estrutural das desigualdades sociais:

Seria preciso entender as categorias de raça, gênero, classe e sexualidade como elementos da estrutura social que emergem como dispositivos fundamentais que favorecem as desigualdades e criam grupos em vez de pensar essas categorias como descritivas da identidade aplicada aos indivíduos. (RIBEIRO, 2017, p. 61)

Para Dijamila Ribeiro, é importante levar em conta que os discursos identitários precisam ser pensados pelo prisma da descolonização do conhecimento, descolonização epistêmica. A identidade deve então ser concebida como identidade social, historicamente produzida por relações de poder que legitimam ou deslegitimam certas identidades. Em seu recém-publicado livro “O que é lugar de fala?” (2017), Ribeiro argumenta que o entendimento de "lugar de fala" é mais que uma reivindicação de "ponto de vista", é também a construção de novas epistemologias nos círculos acadêmicos, que produzem análises políticas e sociais, um meio de "refutar a historiografia tradicional e a hierarquização dos saberes consequente da hierarquia social.”(RIBEIRO, 2017, p.64)

O "lugar de fala", segundo Ribeiro, é marcado pelo grupo social e o contexto histórico em que esse grupo se insere, ou seja, "Não se trataria de afirmar as experiências individuais, mas de entender como o lugar social que certos grupos ocupam restringem oportunidades." (RIBEIRO, 2017, p.61) Assim, o "lugar de fala" não se restringiria ao "falar", mas se ampliaria ao reconhecimento de qualquer espaço social e político, de territórios físicos e simbólicos.

O termo "política" possui ampla aplicação conceitual e neste trabalho se assume principalmente no entendimento de que as disputas em rede cruzam diversas esferas de produção macropolítica e micropolítica, esta última entendida por Guattari e Rolnik, ou seja, como produção de desejo e de sua visibilidade no campo social (GUATTARI; ROLNIK, 1999, p.127). São produzidas no interior das relações entre humanos, (e nãohumanos), mediadas por tecnologias sociais e digitais, mas também pelo dissenso, por corpos subjugados e subjagadores. 
É também a partir das relações entre humanos que Hanna Arendt escreve sobre a política, em sua observação de algo que não é essencial ao humano, mas construído mesmo a partir da relação. Arendt, no texto “O que é política?” (1998) fala da política como liberdade. Tomando por base a polis grega, de onde a palavra política tem origem, ser livre era não ser escravo, não pertencer a nenhum dono, e por isso estar apto a praticar a política, a convivência com outros semelhantes, também livres, na polis. A autora marca uma distinção do entendimento comum do zoon politikon, de Aristóteles, em que a política seria inerente ao ser-humano. Arendt afirma que a política surge na relação, no "entre-humanos", como explica: "a política surge no intra-espaço e se estabelece como relação" (ARENDT, 1998, s/p).

A liberdade, na Antiguidade, era algo muito caro, e por isso, o ser humano deveria lutar contra qualquer coisa que o tornasse escravo, que o tomasse a liberdade. A questão da liberdade está no cerne do pensamento sobre a política, e os "lugares de fala" parecem acionar deslocamentos no social que implicam na construção de um comum para minorias socialmente constituídas, que também revelam práticas de liberdade.

Em Michel Foucault, no debate sobre as "práticas de liberdade", em "Ética, Sexualidade e Política" (2006), o autor discorre sobre o "governo de si", em que a liberdade significa não ser escravo, "de uma outra cidade, daqueles que o cercam, daqueles que o governam, de suas próprias paixões" (2006, p.268). O cuidado de si pressupõe uma ética própria de si para consigo e para com os outros, que se revela como prática de liberdade, já que para o ser livre era preciso ser, em primeiro lugar, livre de vícios e paixões.

A liberdade também marcava a distinção entre quem podia falar e fazer a política, quem podia "conversar livremente", nos termos de Arendt, ou quem estava determinado a trabalhar e sustentar essa organização da polis, os escravos, que serviam para "liberar" os "políticos" do trabalho manual, discussão que também aparece em Rancière. É também com base na democracia grega da Antiguidade que o autor reflete que o comum nem sempre poderia ser acessado, uma vez que participar do comum diz respeito a quem vê e quem diz, e sobre quem pode ver e quem pode dizer. Essa condição torna-se política na medida em que poder ver e poder dizer dependerá da ocupação que o indivíduo tem na sociedade. Um artesão não poderá ver nem dizer 
publicamente, na ágora, pois dedica a maior parte do seu tempo ao trabalho. (RANCIÈRE, 2005).

Este debate nos ajuda a entender que a política está intimamente ligada à liberdade. Seja na concepção de não ser escravo, (nem de outra pessoa nem de si mesmo), que aponta para uma ética política e social, ou na concepção de liberdade como meio de partilhar o comum, que aponta para questões como a dos privilégios sociais e dos "lugares de fala".

Neste aspecto, é interessante notar que o território físico do Beco do Rato, na Lapa, onde o imóvel da Casa Nem (antes Nuvem) está localizada, foi repetidamente reivindicado na fala da liderança LGBTI, Indianara Siqueira, como reconhecimento de um espaço social e historicamente pertencente às prostitutas transexuais e travestis no Rio de Janeiro. Então, o território físico da casa, da rua, do beco, do bairro, da cidade, traz ênfase ao território simbólico, que também é construído a partir de discursividades, que em nossa investigação aparece pelo prisma das disputas de narrativas online.

\section{Considerações finais}

O que parece estar em jogo nas disputas de narrativas que se dão em rede, especificadas por um recorte do caso Casa Nuvem - Casa Nem, é que a produção de modos de vida, de visões de mundo e de sujeitos políticos nos dias de hoje também é atravessada pela experiência das tecnologias digital e online. E que tal maneira nos mostra o quanto, por sua vez, esses usos das tecnologias são eles próprios construídos e atravessados, por sua vez, por outras forças, subjetivas, simbólicas, corpóreas, políticas, econômicas, históricas. Especialmente ao que concerne à insurgência de novos sujeitos políticos, descentralizados e fragmentados, que disputam territórios discursivos e performativos, dando a ver a produção do dissenso como algo inerente à política e mesmo como seu "comum". O que situações como as que trouxemos aqui parecem nos mostrar é que desentendimento, dissenso e controvérsia são qualidades potencializadoras de dinâmicas sociais e políticas, uma vez que impedem a cristalização do consensual. Assim, também entendemos que as partilhas do sensível são agenciamentos políticos importantes para a manutenção das lutas políticas por liberdades. Liberdade como direito ao corpo, à cidade, à vida. 


\section{Referências Bibliográficas}

ARENDT, Hannah. O que é política? In: O que é política? - fragmentos de obras póstumas. Rio de Janeiro: Bertrand Brasil, 1998. (21 - 84)

EUGÊNIO, Fernanda; FIADEIRO, João. Jogo das perguntas: o modo operativo 'And' e o viver juntos sem ideias. In: PASSOS, Eduardo; KASTRUP, Virgínia; TEDESCO, Silvia (Org.). Pistas do método da cartografia: a experiência da pesquisa e o plano comum. Vol.2. Porto Alegre: Sulina, 2014.

FOUCAULT, Michel. Ética, sexualidade, política. Tradução de Elisa Monteiro, Inês Dourado Barbosa. 2. ed. Rio de Janeiro: Forense Universitária, 2006.

GOHN, Maria da Glória. Movimentos sociais no início do século XXI. Petrópolis: Vozes, 2003.

LATOUR, Bruno. Reensamblar lo Social : una introducción a la teoría del actor-red. 1 ed. Buenos Aires : Manantial, 2008.

MELUCCI, Alberto. Mouvements, crise de la politique et nouveaux militants. Paris: La Découverte, 1999.

NEGRI, Antonio; HARDT, Michael. Declaração: isto não é um manifesto. São Paulo: n-1, 2016.

RANCIÈRE, Jacques. A partilha do sensível: estética e política. São Paulo: Ed.34, 2005 O desentendimento: política e filosofia. São Paulo: Ed.34, 1996.

O dissenso. In: A crítica da razão. São Paulo: Companhia das Letras; Brasília: Ministério da Cultura; Rio de Janeiro: Fundação Nacional de Arte, 1996. (367-382).

RIBEIRO, Djamila. O que é lugar de fala ? Belo Horizonte : Letramento, 2017.

ROLNIK, Suely; GUATTARI, Félix. Cartografias do desejo. Petrópolis: Vozes, 2011.

SODRÉ, Muniz. A Ciência do Comum: notas para o método comunicacional. Petrópolis: Vozes, 2014. 